\title{
Isocratic Reverse-Phase HPLC Method for Determination of Aspirin, Paracetamol, and Naproxen
}

\author{
Md. Mynul Hassan ${ }^{1}$ and Sung-Wook Nam ${ }^{1, *}$ \\ 1 Department of Molecular Medicine, School of Medicine, Kyungpook National University, Daegu 41405, \\ Republic of Korea; mynulhasan89@gmail.com (M.M.H.) \\ * Correspondence: nams@knu.ac.kr
}

\begin{abstract}
Nonsteroidal anti-inflammatory drugs (NSAIDs), which block the activity of cyclooxygenase (COX) isoenzymes and inhibit the synthesis of prostaglandin, have been used for pain relief. We have developed a method to separate a mixture of three NSAIDs, such as aspirin, paracetamol, and naproxen, using reverse-phase high-performance liquid chromatography (RP-HPLC). An isocratic mobile phase consisting of acidic water and acetonitrile was selected to run at a low flow rate, such as $0.8 \mathrm{~mL} / \mathrm{min}$. The mixture of three NSAIDs was injected at a low volume into a C18 column that was $150 \mathrm{~mm}$ in length and characterized using a UV detector at $230 \mathrm{~nm}$. We identified three peaks in the chromatogram indicating the three compounds. The elution time of the peaks was less than $10 \mathrm{~min}$. To identify multiple peaks on the isocratic flow using a short column, further studies are required regarding the proposed method to generate microfluidic devices for nanoLC.
\end{abstract}

Keywords: HPLC; NSAIDs; Isocratic; Short column; Drug mixture

\section{Introduction}

As the use of multi-component drugs increases in medicine, there is a need for a quantitative method to analyze the components in a drug mixture accurately [1-5]. Chromatography, a method that separates a mixture of ingredients based on their molecular structure and composition, has been widely used for protein purification and antibody separation [6,7]. In combination with mass spectrometry, chromatography has been an essential part of proteomic analysis. [8-13]. High-performance liquid chromatography (HPLC) has been adapted to analyze multi-component drugs by adjusting the affinity between the surfactant of column beads and the drug molecules according to size and electric charges. The microfluidic-based nanoLC method has recently become a powerful tool for the simultaneous determination of the chemical compounds in a mixture [14-17].

Nonsteroidal anti-inflammatory drugs (NSAIDs) are regarded as cyclooxygenase (COX) inhibitors and generally prescribed as pain relievers for headaches, rheumatoid arthritis, postoperative pain, and orthopedic fractures [18-20]. Despite NSAIDs' beneficial effects, their use has been limited due to their side effects, such as mucosal injury to the gastrointestinal tract and the risk of thrombotic cardiovascular events [21-25]. Aspirin (2acetoxybenzoic acid), paracetamol ( $\mathrm{N}$-acetyl-para-aminophenol), and naproxen [(S)-(+)-2(6-Methoxy-2-naphthyl) propionic acid] are classic NSAIDs available in local drug stores. The chemical structures are shown in Figure 1. Tablets with a fixed-dose combination of NSAIDs with caffeine are more effective than the individual NSAIDs [2,3]. Also, NSAID mixtures with gastric ulcer reducers, such as omeprazole, esomeprazole, and pantoprazole acting as proton pump inhibitors, are broadly used to reduce the gastric side effect of NSAIDs $[1,4,5]$. Therefore, there is growing research on the simultaneous analysis of drug mixtures using chromatography. 
(a)<smiles>CC(=O)Oc1ccccc1C(=O)O</smiles>

Aspirin (b)<smiles>CC(=O)Nc1ccc(O)cc1</smiles>

Paracetamol (c)<smiles>COc1ccc2cc(C(C)C(=O)O)ccc2c1</smiles>

Figure 1. The structures of (A) 2-Acetoxybenzoic acid (aspirin), (B) N-acetyl-para-aminophenol (paracetamol), (C) (S)-(+)2-(6-Methoxy-2-naphthyl) propionic acid (naproxen).

HPLC methods have been used for the quantitative and qualitative analysis of NSAIDs [26-40]. Isocratic methods are used to determine one or two compounds, while gradient methods are used for multiple drugs [26]. However, it is challenging to separate the multiple components in a drug with an isocratic method using a short column. Here we present an isocratic RP-HPLC method that determines the aspirin, paracetamol, and naproxen in a combined solution. This method provides a timely and cost-effective way to determine the NSAIDs with its combination with other drugs.

\section{Materials and Methods}

\subsection{Chemicals and solvents}

HPLC grade acetonitrile (Honeywell Burdick \& Jackson, Ulsan, Korea), and analytical reagent grade orthophosphoric acid $85 \%$, potassium dihydrogen phosphate, and triethylamine (Merck, Darmstadt, Germany) were purchased. Water was purified using a Smart2Pure (Thermo Scientific) system. The mobile phase was filtered using PTFE membrane filter of $0.45 \mu \mathrm{m}$ pore size. Each aspirin (Bayer Bitterfeld $\mathrm{GmbH}$ ), paracetamol (Janssen Korea Ltd.), and naproxen (Chong Kun Dang Pharma, Korea) tablet contains 500 $\mathrm{mg}$ of active pharmaceutical ingredient (API).

\subsection{First dilution to prepare stock solutions of aspirin, paracetamol, and naproxen}

The first dilution procedures to prepare stock solutions are described in Figure 1(a). For aspirin, paracetamol, and naproxen tablets, 10 tablets of each drug were ground to a fine powder using a glass mortar and pestle. Aspirin $(60.0 \mathrm{mg})$, paracetamol $(30.3 \mathrm{mg})$, and naproxen $(52.0 \mathrm{mg}$ ) were transferred to $100 \mathrm{~mL}$ volumetric flask each. A mixture of acetonitrile and water at a ratio of 70:30 was used as a diluent. Approximately, $75 \mathrm{~mL}$ of diluent was added to each volumetric flask. The solutions were shaken and sonicated for $15 \mathrm{~min}$. After cooling down the solution, the $100 \mathrm{~mL}$ volumetric flasks were completely filled with the diluent. Each solution was stored as a stock solution of aspirin, paracetamol, and naproxen.

\subsection{Second dilution by mobile phases to prepare individual drug solutions}

The second dilution procedure was conducted to prepare individual drug solution as shown in Figure 1(b). From each stock solution of aspirin, paracetamol, and naproxen, $2 \mathrm{~mL}$ was transferred to each $50 \mathrm{~mL}$ volumetric flask. Then, the volumetric flasks were completely filled with different mobile phases. The mobile phase solutions consisted of acidic water and acetonitrile with different ratios and $\mathrm{pH}$, depending on the individual drug components as listed in Table 1 . By considering the $\mathrm{pKa}$ values of aspirin, paraceta$\mathrm{mol}$, and naproxen, the $\mathrm{pH}$ concentrations of the mobile phases were carefully controlled. The $\mathrm{pH}$ was adjusted by adding phosphoric acid to the ultrapure water. The second-diluted solutions of the individual drugs were transferred to the HPLC vial via $0.25 \mu \mathrm{m}$ PTFE filters. 


\subsection{Drug mixture}

For preparing the drug mixture, $2 \mathrm{~mL}$ stock solutions of aspirin, paracetamol, and naproxen are combined in a $50 \mathrm{~mL}$ volumetric flask, as shown in the right-hand-side panel in Figure 2(b). The flask was completely filled with a mobile phase solution. For the drug mixture solution, the mobile phase consisted of acidic water ( $\mathrm{pH} 2.5)$ and acetonitrile at the ratio of 85:15, as noted in Table.1. The drug mixture solution was transferred to the HPLC vial through a $0.25 \mu \mathrm{m}$ PTFE filter.

(a) Aspirin (ASP)
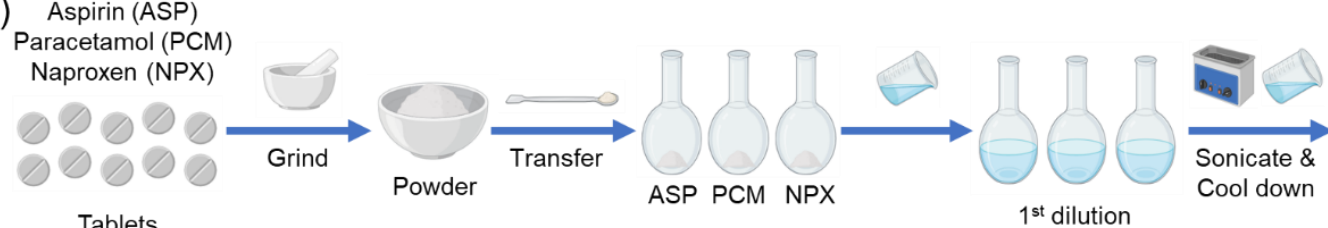
(Acetonitrile:Water $=70: 30$ )

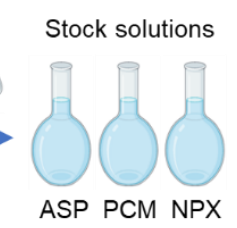

(b)
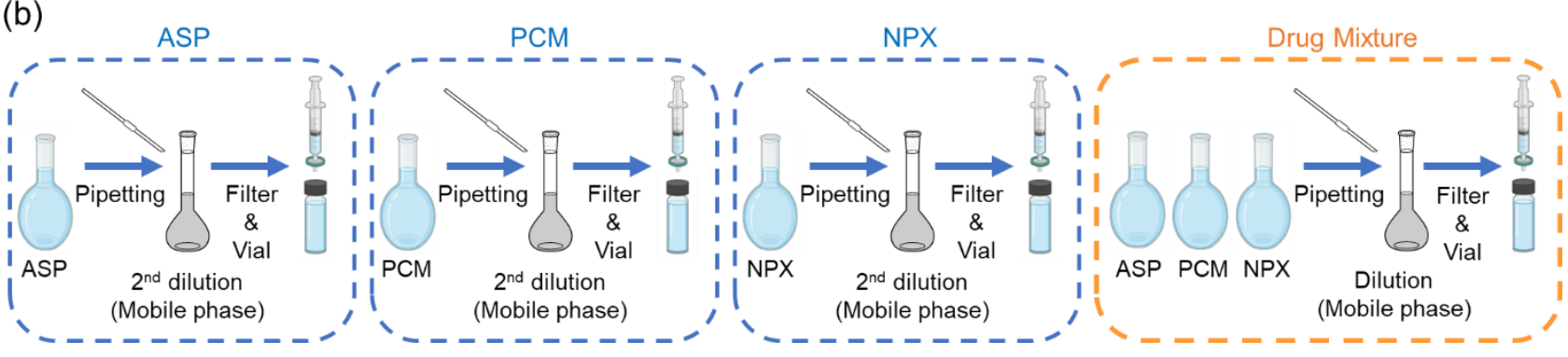

(c)

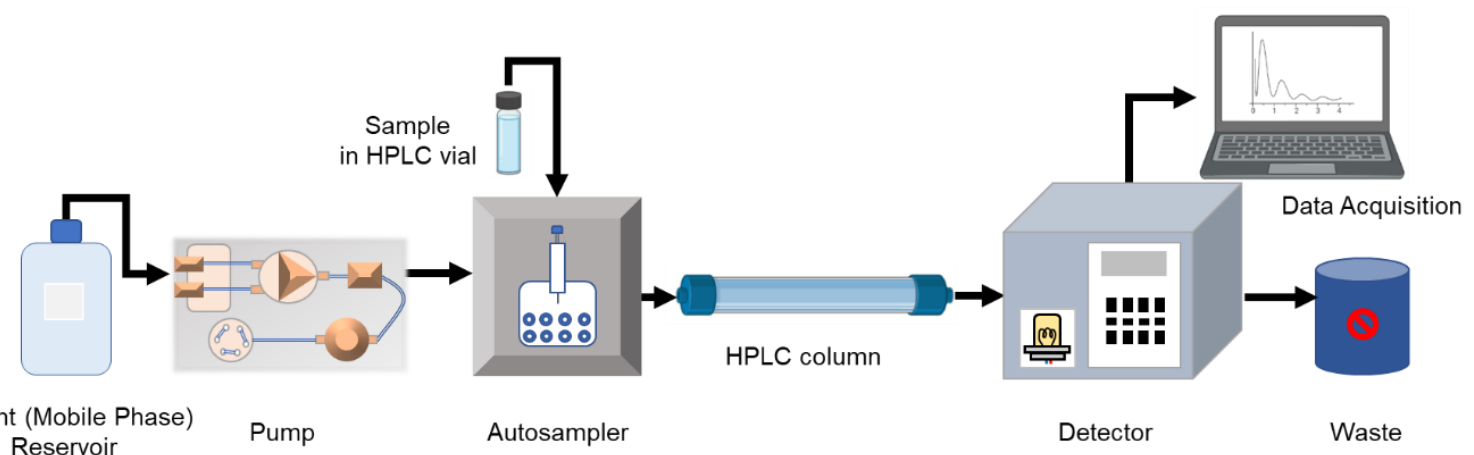

Figure 2. (a) First dilution of aspirin, paracetamol, and naproxen to prepare stock solutions, (b) Second dilution and drug mixture preparation. (c) A schematic of high-performance liquid chromatography (HPLC). A reservoir holds the solvent, and a high-pressure pump is used to generate and meter a specified flow rate of the mobile phase. An injector introduces the sample into the mobile phase for the sample to pass through the HPLC column. The UV detector detects the separated compound bands as they are eluted from the HPLC column.

\subsection{HPLC instrumentation}

As described in Figure 2(c), the Waters HPLC system includes a gradient multi-solvent delivery system (Delta 600), helium degasser, Waters 717plus Autosampler, and a UV/VIS detector model 2489. A Waters Empower 2 software was used to control the system. HPLC analysis was conducted isocratically at room temperature using a Waters Atlantis C18 $(150 \mathrm{~mm} \times 4.6 \mathrm{~mm}, 3 \mu \mathrm{m})$ column.

\subsection{Chromatographic conditions}

The mobile phase consisted of ultra-pure water of variable $\mathrm{pH}$ and acetonitrile. The $\mathrm{pH}$ was adjusted for individual optimum run conditions. The flow rate was varied from 0.8 to $1.0 \mathrm{~mL} / \mathrm{min}$ and the eluent was monitored with an UV detector ranging 230 to 260 $\mathrm{nm}$. The detailed chromatographic conditions are elaborated in Table 1. 
Table 1. Chromatographic conditions for nonsteroidal anti-inflammatory drugs.

\begin{tabular}{|c|c|c|c|c|}
\hline & Aspirin & Paracetamol & Naproxen & Mixture \\
\hline Stationary phase & $\begin{array}{c}\mathrm{C} 18(150 \mathrm{~mm} \times 4.6 \\
\mathrm{mm}, 3 \mu \mathrm{m})\end{array}$ & $\begin{array}{c}\mathrm{C} 18(150 \mathrm{~mm} \times 4.6 \\
\mathrm{mm}, 3 \mu \mathrm{m})\end{array}$ & $\begin{array}{c}\mathrm{C} 18(150 \mathrm{~mm} \times 4.6 \\
\mathrm{mm}, 3 \mu \mathrm{m})\end{array}$ & $\begin{array}{c}\mathrm{C} 18(150 \mathrm{~mm} \times 4.6 \\
\mathrm{mm}, 3 \mu \mathrm{m})\end{array}$ \\
\hline Detector-Wavelength & UV $230 \mathrm{~nm}$ & UV $260 \mathrm{~nm}$ & UV $230 \mathrm{~nm}$ & UV $230 \mathrm{~nm}$ \\
\hline Mobile phase & $\begin{array}{l}\text { Acidic water }(\mathrm{pH} 3.0) \\
\text { Acetonitrile }=60: 40\end{array}$ & $\begin{array}{l}\text { Acidic water (pH 3.5): } \\
\text { Acetonitrile }=75: 25\end{array}$ & $\begin{array}{c}\text { Acidic water }(\mathrm{pH} 2.5) \\
\text { Acetonitrile }=87: 13\end{array}$ & $\begin{array}{l}\text { Acidic water (pH 2.5): } \\
\text { Acetonitrile }=85: 15\end{array}$ \\
\hline Flow rate $(\mathrm{mL} / \mathrm{min})$ & 1 & 1 & 1 & 0.8 \\
\hline Injection volume $(\mu \mathrm{L})$ & 10 & 20 & 10 & 15 \\
\hline Run time (min) & 15 & 10 & 10 & 15 \\
\hline
\end{tabular}

\section{Results and Discussion}

\subsection{Net charge of aspirin, paracetamol, and naproxen}

The $\mathrm{pKa}$ values of aspirin, paracetamol, and naproxen are 3.41, 9.46, and 4.19, respectively. As shown in Figure 1, aspirin and naproxen have a $\mathrm{COOH}$ group as an acid functional group. In contrast, paracetamol has a $-\mathrm{NH}-$ group as a basic functional group. Therefore, in an acidic solution, that is, in a solution having a $\mathrm{pH}$ value of approximately $\leq 3$, the net charge of aspirin and naproxen is 0 , whereas paracetamol has a net charge of +1 .

\subsection{The polarity of drug molecule}

As shown in Figure 1, naproxen has two conjugated phenyl rings, whereas aspirin and paracetamol have one phenyl ring each. Furthermore, in the analysis of the dipole moment among atoms based on the difference in the electronegativity, it is noticed that paracetamol has the functional groups of $-\mathrm{OH},-\mathrm{NH}-, \mathrm{C}=\mathrm{O}$, in which $\mathrm{O}$ and $\mathrm{N}$ have relatively large electronegativity values. Interestingly, all $\mathrm{O}$ and $\mathrm{N}$ atoms are directed downwards, implying the enhancement of polarity.

Aspirin has $\mathrm{COOH}$ and one ester bond, paracetamol has one $\mathrm{OH}$ and one amide bond, and naproxen has one $\mathrm{COOH}$ functional group. In terms of coordination of the functional groups, paracetamol is expected to be the most polar molecule among them. In naproxen, there are two conjugate rings with only one polar functional group; thus, the polarity is expected to be the lowest.

\section{Molecular polarity: Paracetamol $>$ Aspirin $>$ Naproxen}

The prediction is well reflected in the experimental results. As shown in Figure 3, in the case of retention time, paracetamol is the least, followed by aspirin and naproxen. Since the stationary phase of RP-HPLC is a hydrophobic material such as C18, the greater the polarity of the analyte molecule, the less affinity with the stationary phase, reducing retention time [41]. Table 2 shows the results of RP-HPLC chromatograms for aspirin, paracetamol, and naproxen. Our theory and the experimental results are well-matched. The tendency of the retention time of aspirin, paracetamol, and naproxen are also consistent with the results reported in other studies [26]. 


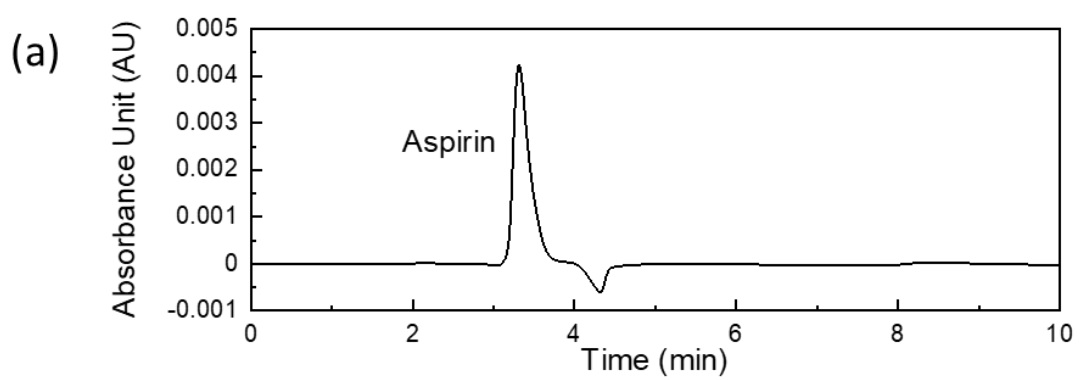

(b)

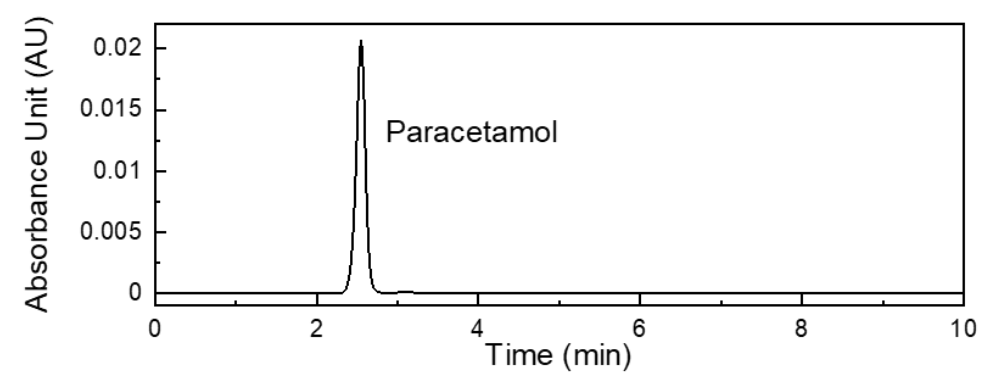

(c)
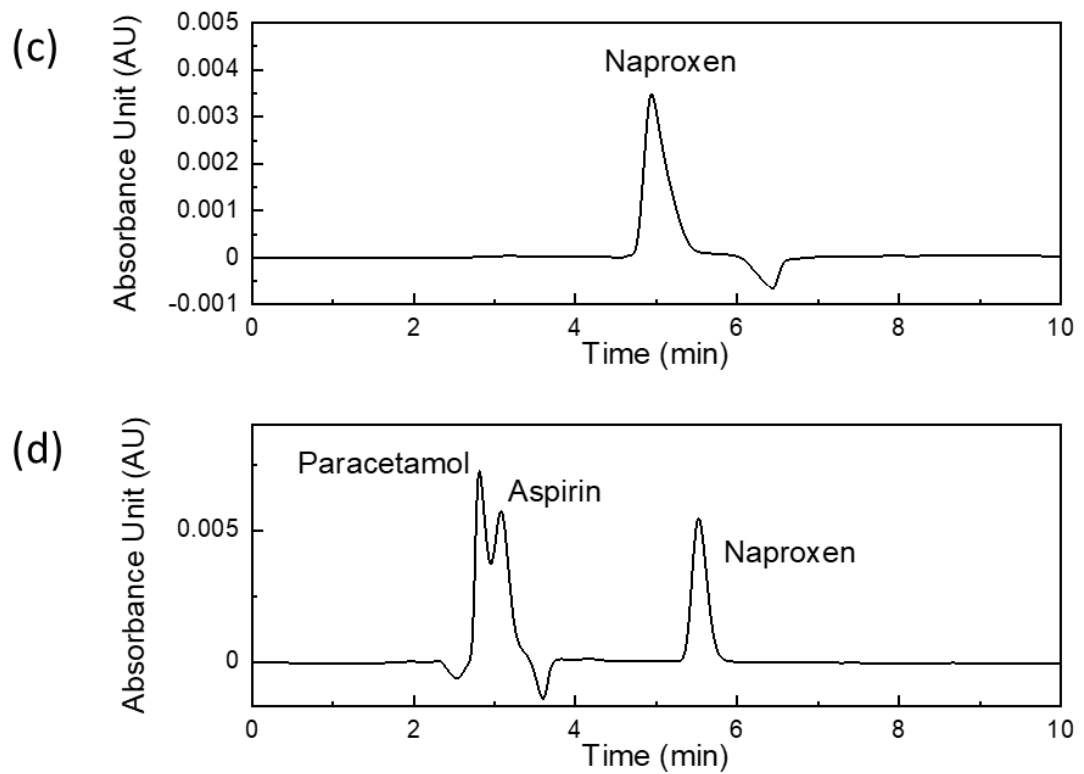

Figure 3. High-performance liquid chromatography (HPLC) chromatograms of the analysis of the nonsteroidal anti-inflammatory drugs showing the separation in the isocratic program. The peak of (A) aspirin, (B) paracetamol, (C) naproxen, and (D) a combination of aspirin, paracetamol, and naproxen.

Table 2. Chromatogram summary of aspirin, paracetamol, naproxen, and their mixture

\begin{tabular}{ccccccc}
\hline & Aspirin & Paracetamol & Naproxen & \multicolumn{3}{c}{ Mixture } \\
\cline { 5 - 6 } & 3.31 & 2.55 & 4.94 & 3.15 & 2.82 & 5.52 \\
\hline $\begin{array}{c}\text { Retention } \\
\text { time (Rt) }\end{array}$ & & - & - & 0.68 & - & 5.28 \\
$\begin{array}{c}\text { Resolution } \\
\text { factor (Rf) }\end{array}$ & - & & & & & \\
$\begin{array}{c}\text { Number of } \\
\text { theoretical } \\
\text { plates (N) }\end{array}$ & 8412 & 7421 & 112180 & 8642 & 7913 & 113582 \\
$\begin{array}{c}\text { Tailing factor } \\
\text { (Tf) }\end{array}$ & 1.13 & 1.05 & 1.22 & 1.31 & Naracetamol & Naproxen \\
\hline
\end{tabular}




\section{Conclusions}

In conclusion, we have developed an isocratic RP-HPLC method to analyze a mixture of NSAIDs, including aspirin, paracetamol, and naproxen. We have identified an optimal isocratic condition for analyzing the mixture of aspirin, paracetamol, and naproxen by adjusting the mobile phase and $\mathrm{pH}$ parameters. The parameter adjusting principle can be used for the identification of combination drugs, such as caffeine and proton inhibitors, with NSAIDs. The protocol described here can also be utilized for the high-resolution separation of drug components by microfluid-based nanoLC technology.

\section{Author Contributions:}

Conceptualization, S.-W.N.; methodology, M.M.H.; formal analysis, S.-W.N. and M.M.H.; investigation, S.-W.N. and M.M.H.; writing, S.-W.N. and M.M.H.; supervision, S.-W.N.; funding acquisition, S.-W.N. All authors have read and agreed to the published version of the manuscript.

Funding: This research was supported by the Bio \&Medical Technology Development Program of the National Research Foundation (NRF) funded by the Ministry of Science \& ICT (2017M3A9G8083382).

Institutional Review Board Statement: Not applicable.

Informed Consent Statement: Not applicable.

Data Availability Statement: The data presented in this study are available on request from the corresponding author

Acknowledgments: We appreciate Prof. In Suk Han for sharing her HPLC instrument.

Conflicts of Interest: The authors declare no conflict of interest.

\section{References}

1. Kamal, A.H.; Marie, A.A.; Hammad, S.F. Stability indicating RP-HPLC method for simultaneous determination of omeprazole and aspirin in the presence of salicylic acid as degradation product. Microchem J. 2020, 152, 104350; DOI: 10.1016/j.microc.2019.104350.

2. Palur, K.; Archakam, S.C.; Koganti, B. Chemometric assisted UV spectrophotometric and RP-HPLC methods for simultaneous determination of paracetamol, diphenhydramine, caffeine and phenylephrine in tablet dosage form. Spectroc. Acta Pt. A-Molec. Biomolec. Spectr. 2020, 243, 118801; DOI: 10.1016/j.saa.2020.118801

3. Aminu, N.; Chan, S.-Y.; Khan, N. H.; Farhan, A. B.; Umar, M. N.; Toh, S.-M. A simple stability-indicating HPLC method for simultaneous analysis of paracetamol and caffeine and its application to determinations in fixed-dose combination tablet dosage form. Acta Chromatogr. 2019, 31, 85-91; DOI: 10.1556/1326.2018.00354.

4. Dhillon, S. Naproxen/Esomeprazole fixed-dose combination. Drugs Aging 2011, 28, 237-248; DOI: 10.2165/11207150-00000000000000.

5. Lanza, F.L.; Chan, F.K.L.; Quigley, E.M.M. Guidelines for prevention of NSAID-related ulcer complications. Am. J. Gastroenterol. 2009,104, 728-738; DOI: 10.1038/ajg.2009.115.

6. Wilson, H.N. Chromatography, In: Wilson H.N.; An Approach to Chemical Analysis; Pergamon, 1966, pp 192-221.

7. Karger, B. L. HPLC: Early and Recent Perspectives. J. Chem. Educ. 1997, 74, 45; DOI: 10.1021/ed074p45.

8. Ventouri, I.K.; Malheiro, D.B.A.; Voeten, R.L.C.; Kok, S.; Honing, M.; Somsen, G.W.; Haselberg, R. Probing protein denaturation during size-exclusion chromatography using native mass spectrometry. Anal. Chem. 2020, 92, 4292-4300; DOI: 10.1021/acs.analchem.9b04961.

9. Hober, S.; Nord, K.; Linhult, M. Protein A chromatography for antibody purification. J. Chromatogr. B 2007, 848, 40-47; DOI: 10.1016/j.jchromb.2006.09.030.

10. Ramos-de-la-Pena, M.; Gonzalez-Valdez, J.; Aguilar, O. Protein A chromatography: Challenges and progress in the purification of monoclonal antibodies. J. Sep. Sci. 2019, 42, 1816-1827; DOI: 10.1002/jssc.201800963.

11. Dal Bello, F.; Mecarelli, E.; Gastaldi, D.; Savino, F.; Medana, C. Nano-HPLC-HRMS Analysis to Evaluate Leptin Level in Milk Samples: A Pilot Study. Appl. Sci. 2020, 10, 6135. https://doi.org/10.3390/app10176135

12. Guć, M.; Schroeder, G. Application of Molecularly Imprinted Polymers (MIP) and Flowing Atmospheric-Pressure Afterglow Mass Spectrometry (FAPA-MS) to Analysis of Nonsteroidal Anti-Inflammatory Drugs (NSAIDs). Appl. Sci. 2020, $10,4217$. https://doi.org/10.3390/app10124217

13. Wazed, M.A.; Farid, M. A Reversed-Phase HPLC Method for Determination of Osteopontin in Infant Formula. Appl. Sci. 2019, 9 , 3711. https://doi.org/10.3390/app9183711

14. Kim, J.Y.; Cho, S.-W.; Kang, D.-K.; Edel, J.B.; Chang, S.-I.; DeMello, A.J.; O’Hare, D. Lab-chip HPLC with integrated dropletbased microfluidics for separation and high frequency compartmentalization. Chem. Commun. 2012, 48, 9144-9146; DOI: 10.1039/C2CC33774F. 
15. Chan, A.S.; Danquah, M.K.; Agyei, D.; Hartley, P.G.; Zhu, Y. A simple microfluidic chip design for fundamental bioseparation. J. Anal. Methods Chem. 2014, 175457; DOI: 10.1155/2014/175457

16. Malsche, W.D.; Eghbali, H.; Clicq, D.; Vangelooven, J.; Gardeniers, H.; Desmet, G. Pressure-driven reverse-phase liquid chromatography separations in ordered nonporous pillar array columns. Anal.Chem. 2007, 79, 5915-5926; DOI:10.1021/ac070352p

17. Gaspar, A.; Piyasena, M.E.; Gomez, F.A. Fabrication of fritless chromatographic microchips packed with conventional reversedphased silica particles. Anal. Chem. 2007, 79, 7906-7909; DOI: 10.1021/ac071106g.

18. Oates, J.A.; Wood, A.J.J; Brooks, P.M; Day, R.O. Nonsteroidal Antiinflammatory Drugs--Differences and Similarities. N Engl J Med. 1991, 324, 1716-1725.

19. Vane, J.R.; Botting, R.M. Mechanism of Action of Nonsteroidal Anti-inflammatory Drugs. Am. J. Med. 1998, 104, 2S-8S, DOI: 10.1016/S0002-9343(97)00203-9.

20. Brune, K.; Patrignani, P.; New insights into the use of currently available non-steroidal anti-inflammatory drugs. J. Pain Res. 2015, 8, 105-118; DOI: 10.2147/JPR.S75160.

21. Coxib and traditional NSAID Trialists' (CNT) Collaboration. Vascular and upper gastrointestinal effects of non-steroidal antiinflammatory drugs: meta-analyses of individual participant data from randomised trials. Lancet 2013, 382, 769-779; DOI: 10.1016/S0140-6736(13)60900-9.

22. Silverstein, F.E.; Faich, G.; Goldstein, et al. Gastrointestinal toxicity with celecoxib vs. nonsteroidal anti-inflammatory drugs for osteoarthritis and rheumatoid arthritis: the CLASS study: a randomized controlled trial. Celecoxib Long-term Arthritis Safety Study. JAMA. 2000, 284, 1247-1255; DOI: 10.1001/jama.284.10.1247.

23. Schjerning, A.-M; McGettigan, P.; Gislason, G. Cardiovascular effects and safety of (non-aspirin) NSAIDs. Nat. Rev. Cardiol. 2020, 17, 574-584, DOI: 10.1038/s41569-020-0366-Z

24. Suyama, Y.; Handa, O.; Naito, Y.; et al. Mucus reduction promotes acetyl salicylic acid-induced small intestinal mucosal injury in rats. Biochem Biophys Res Commun. 2018, 498, 228-233; DOI: 10.1016/j.bbrc.2018.02.202.

25. Ohyama K.; Shiokawa, A.; Ito, K.; Masuyama, R.; Ichibangase, T.; Kishikawa, N.; Imai, K.; Kuroda, N. Toxicoproteomic analysis of a mouse model of nonsteroidal anti-inflammatory drug-induced gastric ulcers. Biochem Biophys Res Commun. 2012, 420, 210215; DOI: 10.1016/j.bbrc.2012.03.009.

26. Patel, P.N.; Samanthula, G.; Shrigod, V.; Modh, S.C.; Chaudhari, J.R. RP-HPLC Method for Determination of Several NSAIDs and Their Combination Drugs. Chromatogr. Res. Int. 2013. DOI: 10.1155/2013/242868.

27. Abdelaleem, E.A.; Abdelwahab, N.S. Validated stability indicating RP-HPLC method for determination of paracetamol, methocarbamol and their related substances. Anal. Methods 2013, 5, 541-545; DOI: 10.1039/C2AY26085A.

28. Youssef, S.H.; Mohamed, D.; Hegazy, M.A.M.; Badawey, A. Analytical methods for the determination of paracetamol, pseudoephedrine and brompheniramine in Comtrex tablets BMC Chem. 2019, 13, 78; DOI: 10.1186/s13065-019-0595-6.

29. Acheampong, A.; Gyasi, W.O.; Darko, G.; Apau, J.; Addai-Arhin, S. Validated RP-HPLC method for simultaneous determination and quantification of chlorpheniramine maleate, paracetamol and caffeine in tablet formulation. SpringerPlus 2016, 5 ,625; DOI: $10.1186 / \mathrm{s} 40064-016-2241-2$.

30. Kayesh, R.; Sultan, M.Z. A novel ion-pair RP-HPLC method for simultaneous quantification of naproxen and esomeprazole in pharmaceutical formulations. J. Chromatogr. Sci. 2015, 53, 687-693; DOI: 10.1093/chromsci/bmu103.

31. Assali, M.; Abualhasan, M.; Zohud, N.; Ghazal, N. RP-HPLC method development and validation of synthesized codrug in combination with indomethacin, paracetamol, and famotidine. Int. J. Anal. Chem. 2020, 2020; DOI: 10.1155/2020/1894907.

32. Patel, D.; Patel, N.; Vaishy, R.; Patel, V.; Solanki, C.; Patel, M. Development and validation of RP-HPLC method for simultaneous estimation of aspirin and esomeprazole magnesium in tablet dosage form. J. Chem. 2013; DOI: 10.1155/2013/751940.

33. Jain, D.K.; Jain, N.; Charde, R.; Jain, N. The RP-HPLC method for simultaneous estimation of esomeprazole and naproxen in binary combination. Pharm. Methods. 2011, 2, 167-172; DOI: 10.4103/2229-4708.90356.

34. Louden, D.; Handley, A.; Taylor, S.; Lenz, E.; Miller, S.; Wilson, I.D.; Sage, A. Reversed-Phase High-Performance Liquid Chromatography Combined with On-Line UV Diode Array, FT Infrared, and 1H Nuclear Magnetic Resonance Spectroscopy and Time-of-Flight Mass Spectrometry: Application to a Mixture of Nonsteroidal Anti-inflammatory Drugs. Anal. Chem. 2000, 72, 3922-3926. DOI: 10.1021/ac000204y.

35. El-Yazbi, F.A.; Amin, O.A.; El-Kimary, E.I.; Khamis, E.F.; Younis, S.E. Simultaneous determination of methocarbamol and aspirin in presence of their pharmacopeial-related substances in combined tablets using novel HPLC-DAD method. Drug Dev. Ind. Pharm. 2019, 45, 265-272; DOI: 10.1080/03639045.2018.1535603.

36. Dang, H.V.; Thu, H.T.T.; Ha, L.D.T.; Mai, H.N. RP-HPLC and UV Spectrophotometric Analysis of Paracetamol, Ibuprofen, and Caffeine in Solid Pharmaceutical Dosage Forms by Derivative, Fourier, and Wavelet Transforms: A Comparison Study. J. Anal. Methods Chem. 2020, 2020, 1-13; DOI: 10.1155/2020/8107571.

37. Hamid, M.H.M.; Elsaman, T. A Stability-Indicating RP-HPLC-UV Method for Determination and Chemical Hydrolysis Study of a Novel Naproxen Prodrug. J. Chem. 2017, 2017; DOI: 10.1155/2017/5285671.

38. Chaudhary, A.; Wang, J., Prabhu, S. Development and validation of a high-performance liquid chromatography method for the simultaneous determination of aspirin and folic acid from nano-particulate systems. Biomed. Chromatogr. 2010, 24, 919-925; DOI: 10.1002/bmc.1386.

39. Sawyer, M.; Kumar, V. A Rapid High-Performance Liquid Chromatographic Method for the Simultaneous Quantitation of Aspirin, Salicylic Acid, and Caffeine in Effervescent Tablets. J. Chromatogr. Sci. 2003, 41, 393-397; DOI: 10.1093/chromsci/41.8.393. 
40. Milani, P. Z.; Jalali, M.B., Tajerzadeh, H., Azarmi, Y., Valizadeh, H. Simultaneous determination of naproxen, ketoprofen and phenol red in samples from rat intestinal permeability studies: HPLC method development and validation. J. Pharm. Biomed. Anal. 2005, 39, 624-630. DOI: 10.1016/j.jpba.2005.04.008.

41. Skoog, D.A.; West, D.M.; Holler, J.F.; Crouch, S.R. Fundamentals of Analytical Chemistry; 9th edn. David Harris, Belmont, 2013. 